\title{
Mild knee osteoarthritis predicts dissatisfaction after total knee arthroplasty: a prospective study of 186 patients aged 65 years or less with 2-year follow-up
}

Sanni Leppänen ${ }^{1,2^{*}}$, Mika Niemeläinen ${ }^{1,2}$, Heini Huhtala ${ }^{3}$ and Antti Eskelinen ${ }^{1,2}$

\begin{abstract}
Background and aims: The incidence of total knee arthroplasty (TKA) is increasing, especially among younger working-age patients. However, dissatisfaction rates in this population are higher than among older patients. The aim of this study was to assess the rates of dissatisfaction and persistent pain after TKA and to evaluate those factors that predict these outcomes.

Material and methods: In total, 186 patients undergoing unilateral TKA aged 65 years or less were enrolled into this prospective observational study with 2-year follow-up. To assess the outcome, the visual analogue scales regarding satisfaction and persistent pain at rest and during exercise were used. In addition, the association between patients' demographics, radiographic severity of knee osteoarthritis (OA), patient-reported outcome measures (PROMs) and dissatisfaction and persistent pain were tested by univariate logistic regression analysis. Mild $\mathrm{OA}$ was defined as Kellgren-Lawrence $(\mathrm{KL})$ grade 2 and severe $\mathrm{OA}$ as $\mathrm{KL}$ grade 3-4. Furthermore, multiple logistic regression analysis was also conducted to test statistically significant relations.

Results: After 2 years, $12 \%(n=23)$ of patients were dissatisfied with the outcome of TKA, $27 \%(n=50)$ reported persistent pain during exercise and $10 \%(n=18)$ at rest. Patients with mild knee OA were significantly more dissatisfied $(28.6 \%)$ than patients with more severe OA $(8.7 \%)(p=0.003)$. Younger patients had an increased risk for both dissatisfaction and persistent pain. Apart from KOOS Quality of Life, poor preoperative KOOS subscores were also predictive for these outcomes.

Conclusion: Mild radiographic knee OA was the main predicting factor for dissatisfaction after TKA. Thus, performing TKA for such patients should be carefully considered. Furthermore, these patients should be informed about the increased risk for dissatisfaction and the same seems to apply to younger patients. Interestingly, when TKA is performed for patients with more severe knee OA, the satisfaction rates seem to be somewhat higher than those previously reported.
\end{abstract}

\footnotetext{
* Correspondence: sanni.leppanen@fimnet.fi

'Coxa Hospital for Joint Replacement, Tampere, Finland

${ }^{2}$ Faculty of Medicine and Health Technologies, Tampere University, Tampere, Finland

Full list of author information is available at the end of the article
}

(c) The Author(s). 2021 Open Access This article is licensed under a Creative Commons Attribution 4.0 International License, which permits use, sharing, adaptation, distribution and reproduction in any medium or format, as long as you give appropriate credit to the original author(s) and the source, provide a link to the Creative Commons licence, and indicate if changes were made. The images or other third party material in this article are included in the article's Creative Commons licence, unless indicated otherwise in a credit line to the material. If material is not included in the article's Creative Commons licence and your intended use is not permitted by statutory regulation or exceeds the permitted use, you will need to obtain permission directly from the copyright holder. To view a copy of this licence, visit http://creativecommons.org/licenses/by/4.0/ The Creative Commons Public Domain Dedication waiver (http://creativecommons.org/publicdomain/zero/1.0/) applies to the data made available in this article, unless otherwise stated in a credit line to the data. 
Trial registration: The study was retrospectively registered with ClinicalTrials.gov (registration number NCT0323362 0) on 28 July 2017.

Keywords: Knee arthroplasty, Outcome, Satisfaction, Pain, 65 years or less, Young patients, Patient-reported outcome measures

\section{Background}

Recent studies clearly indicate that the incidence of total knee arthroplasty (TKA) will increase in the near future [13]. Indeed, an increasing number of TKAs are being performed not only for older patients but also for younger patients, and the largest proportional increase is reported to be in patients younger than 65 years of age [2]. While TKA has been shown to be an effective treatment for end-stage knee osteoarthritis (OA), younger age is known to be associated with an increased risk for both adverse outcomes and revision surgery [4-6]. Furthermore, younger patients often have high expectations for the outcome of TKA, and this may predispose them to dissatisfaction after the operation [7-10]. The aim of this prospective observational study was to assess which preoperative factors predict dissatisfaction in patients aged 65 years or less undergoing TKA. Primary outcomes were satisfaction and persistent pain as measured with the visual analogue scale (VAS).

\section{Materials and methods}

For the original 2-year prospective cohort study assessing the results of unilateral and bilateral TKAs and UKAs, 255 patients scheduled for knee arthroplasty were enrolled between 1st March 2012 and 30th October 2014 at our high-volume academic tertiary referral centre [11].

The inclusion criteria of the original study cohort were as follows: (1) Age 65 or less and (2) scheduled for knee arthroplasty for primary OA [11]. The exclusion criteria were as follows: (1) rheumatoid arthritis or other inflammatory diseases (2) post-traumatic OA (3) unwilling to provide informed consent (4) physical, mental, or neurological conditions that could compromise the patient's ability and compliance with postoperative rehabilitation and follow-up (e.g., drug or alcohol abuse, serious mental illness, general neurological conditions, such as Parkinson's disease and multiple sclerosis) (5) known sensitivity to the materials used in the devices [11].

\section{Patient flow}

For the purposes of this study, bilateral TKAs and unicompartmental knee arthroplasties were excluded, leaving 205 unilateral TKA patients to be included. Two patients (1\%) died during follow-up. Three patients did not return questionnaires, despite repeated requests, and were therefore considered unwilling to continue in the study. Thus, two hundred patients were available for the 2-year follow up visits, which were carried out via questionnaires by mail. However, 14 patients (7\%) returned only partially completed questionnaires and had left the visual analogue scales regarding satisfaction and persistent pain. These patients were also excluded, and the analysis of the final results was based on 186 (91 \%) TKAs (Fig. 1).

All operations were performed by senior orthopaedic surgeons, and all patients were treated with the same routine postoperative rehabilitation and pain management protocol.

\section{Implants used}

The 186 patients underwent cemented TKA using either PFC (151 knees; DePuy Synthes, Warsaw, IN) or Nexgen (35 knees; Zimmer Biomet, Warsaw, IN). In 8 (4\%) of the TKAs, the patella was resurfaced due to perioperative maltracking. Primary implant was cruciate retaining (CR) model in all patients but posterior stabilised (PS) implants were used if PCL insufficiency was detected peroperatively. Of the 186 TKAs, 177 (95\%) were CR and the remaining 9 were PS.

\section{Outcome measures}

The visual analogue scale (VAS) was measured with a scale from 0 to 100 . It is widely used for evaluating pain intensity and in this study was used to evaluate pain both at rest and during exercise. Satisfaction regarding the studied knee was also measured with VAS as was done by Scott et al. and it is shown to be a reliable method for measuring satisfaction $[9,12]$. All VASs were collected pre- and 2 years postoperatively. When evaluating pain, a score of 100 indicated the worst possible pain. When evaluating satisfaction, a score of 100 indicated the best possible satisfaction. In univariate analysis, dissatisfied patients were defined as satisfaction VAS $\leq 50$ and patients experiencing pain as pain VAS $>30$, respectively $[9,13]$. The minimal clinical important difference (MCID) for measuring pain with VAS is 10 points [13].

Patients were asked to fill out a background questionnaire that included information on working status and physical activities. Medical comorbidities were asked as "Do you have any other conditions that limit your physical activity more than your diagnosed knee osteoarthritis? Yes/No". Patients were also asked to fill three additional PROMs both pre- and postoperatively: the Oxford Knee Score (OKS) [14], the Knee injury and Osteoarthritis Outcome Score (KOOS) [15] and the RAND 36-Item Health Survey (RAND-36) [16]. 


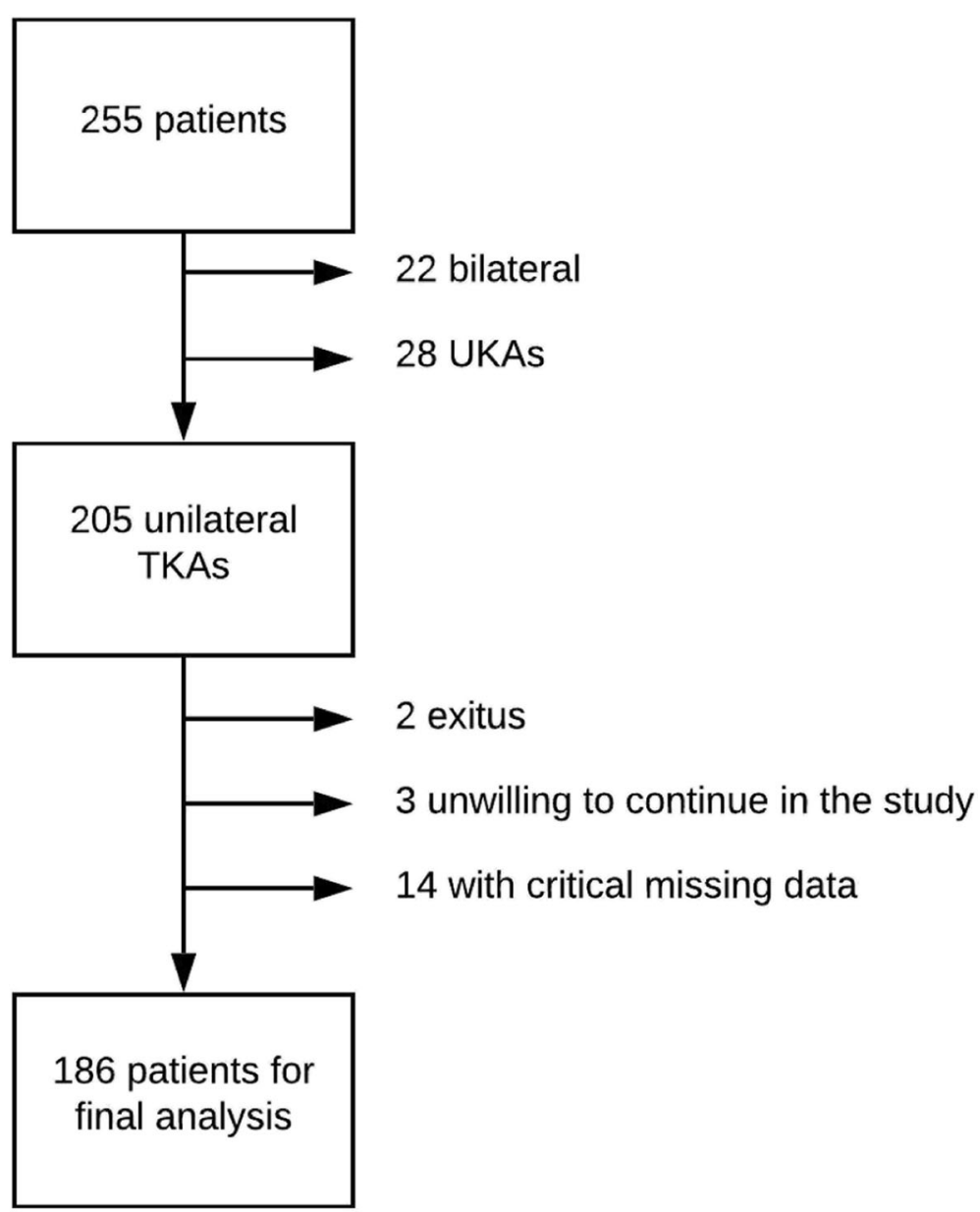

Fig. 1 Patient flow diagram

The severity of knee OA was assessed from preoperative standing fixed flexion view (FFV) radiographs using the Kellgren-Lawrence (KL) classification [17]. Mild knee OA was defined as KL grade 2 and severe knee OA as $\mathrm{KL}$ grade 3-4 [17]. The varus/valgus alignment was assessed from long-leg radiographs.

\section{Statistical analysis}

Demographic data were presented as the median with quartiles $\left(\mathrm{Q}_{1}\right.$ to $\left.\mathrm{Q}_{3}\right)$, range (min to max), or as mean (CI $95 \%$ ). The KOOS scores were divided into five subscale scores (pain, other symptoms, function in daily living (ADL), function in sport and knee related quality of life (QoL)) and were analysed separately. RAND-36 questionnaire scores were divided into two subscale scores (Physical Component Score (PCS) and Mental Component Score (MCS)) and were analysed separately. Univariate logistic regression was used to evaluate the association between the preoperative factors and dissatisfaction and persistent pain. Fisher's exact test was used to compare the dissatisfaction rates, the achieved MCID rates and the prevalence of comorbidities between the KL 2 and KL 3-4 subgroups. Multiple logistic regression analysis was also used to compare the dissatisfaction rates between these two KL subgroups adjusted with age, gender and BMI, which are known or potential risk factors for more severe knee OA, and were thus considered as confounding factors [18-21]. A $p$-value less than 0.05 was considered statistically significant. Data were analysed using the SPSS (version 26) statistical package (IBM, Armonk, NY, USA.).

The study was retrospectively registered with ClinicalTrials.gov (registration number NCT03233620) on 28/ $07 / 2017$. All methods were performed according to the relevant guidelines and regulations and the reporting guideline Strobe was used [22, 23].

\section{Results}

Patients' demographics are shown in Table 1. 
Table 1 Patient $(n=186)$ demographics

\begin{tabular}{lcl}
\hline & median/n & range/\% \\
\hline Age (years) & 60 & $28-65$ \\
BMI & 31 & $20-54$ \\
Females & 117 & 63 \\
Kellgren-Lawrence & & \\
KL 2 & 36 & 19 \\
KL 3 & 87 & 47 \\
KL 4 & 63 & 34 \\
Preoperative varus alignment & 127 & 68 \\
At work preoperatively & 92 & 50 \\
Comorbidities limiting physical activity & 28 & 15 \\
\hline
\end{tabular}

Dissatisfaction: prevalence and relations to demographics At the time of the 2-year follow-up, $12.4 \%(n=23)$ of the patients were dissatisfied with their operated knee. Those patients with mild radiographic knee OA were significantly more dissatisfied than patients with more severe knee OA (28.6\% vs. $8.7 \%, p=0.003$; Table 2), and the risk for dissatisfaction among these patients was more than 4.2-fold (OR 4.22, $95 \%$ CI 1.67-10.66, $p=$ 0.002; Table 3). Furthermore, this difference also persisted in the multiple logistic regression analysis adjusted with age, gender and BMI (OR 4.58, 95 \% CI 1.72-12.20, $p=0.002)$. There was also no difference in prevalence of comorbidities limiting physical activity between mild and severe OA subgroups $(17,1 \%$ vs. $15.0 \%, p=0.795)$. Patients with more severe knee OA also showed a trend to more often achieve clinically significant improvement (exceeding MCID) in VAS satisfaction between the preoperative and the 2-year measurements. This finding, however, lacked statistical significance (Table 2). Younger age also significantly increased the risk for dissatisfaction (OR 0.92, $95 \%$ CI 0.85-0.99, $p=0.029$ ).

Persistent pain: prevalence and relations to demographics At 2 years postoperatively, $27 \%(n=50)$ of patients reported persistent knee pain during exercise and $10 \%$

Table 2 Proportion of dissatisfied patients and MCID ( $\triangle 10$ points) in different KL-groups measured with satisfaction VAS (0100)

\begin{tabular}{|c|c|c|c|c|c|}
\hline & \multicolumn{4}{|c|}{ Kellgren-Lawrence (KL) classification } & \multirow[t]{4}{*}{$p$-value } \\
\hline & \multirow{2}{*}{\multicolumn{2}{|c|}{$\frac{2}{n=35}$}} & \multirow{2}{*}{\multicolumn{2}{|c|}{$\frac{3-4}{n=150}$}} & \\
\hline & & & & & \\
\hline & $\%$ & $\mathbf{n}$ & $\%$ & n & \\
\hline Dissatisfied & 28.6 & 10 & 8.7 & 13 & 0.003 \\
\hline $\mathrm{MCID}^{\mathrm{a}}$ & 90.0 & 27 & 97.2 & 140 & 0.100 \\
\hline
\end{tabular}

Proportion of patients whose satisfaction with their knee improved more than MCID (10 points in VAS satisfaction) from the preoperative evaluation to the 2-year follow-up $(n=18)$ at rest, respectively. Younger age was significantly associated with persistent pain both during exercise (OR 0.93, $95 \%$ CI 0.87-0.99, $p=0.022$ ) and at rest (OR 0.84, $95 \%$ CI $0.77-0.93, p<0.001$ ). Other demographic factors had no effect (Table 3 ).

\section{PROMs relations to dissatisfaction and persistent pain}

Using univariate logistic regression analysis, we also assessed whether preoperative PROMs predicted dissatisfaction and persistent pain at 2 years postoperatively (Table 4). We found that the more pain the patient experienced and the more symptomatic the knee was preoperatively (according to KOOS pain and symptoms subscores), the less likely they were to be satisfied and the more likely they were to suffer from persistent pain at 2 years. Also, weaker sports function (KOOS sport) and function in daily living (KOOS ADL) were statistically significantly related to both dissatisfaction and persistent pain. We also found lower OKS to be associated with persistent pain at rest (OR 0.88, CI $95 \% 0.81-0.96$, $p=0.004$ ) and similar tendencies were also found regarding dissatisfaction and persistent pain during exercise. Both poor mental and physical state, measured with RAND-36 MCS and PCS, were associated with persistent pain at rest, the latter also exceeding the threshold for statistical difference. In addition, lower RAND-36 PCS showed a similar tendency with dissatisfaction and persistent pain during exercise. As we found age to be associated with dissatisfaction and persistent pain, we conducted also age adjusted multiple logistic regression analysis to further assess the relations between preoperative PROMs and dissatisfaction and persistent pain. All the reported findings persisted, apart from the relations between RAND-36 and persistent pain at rest, as the statistical significance was lost (OR 0.97, CI $95 \% 0.93-$ 1.00, $p=0.076)$.

\section{Discussion}

The number of TKAs is rapidly increasing, especially among younger patients [24]. This may be due to the decreasing numbers of high tibial osteotomy and arthroscopic surgery of the degenerative knee $[25,26]$. Thus, patients with milder knee OA may nowadays be more often referred to knee arthroplasty. Previous studies have persistently shown that a varying percentage of patients undergoing TKA end up being unsatisfied with their operated knee $[9,27,28]$. In a systematic review of TKA in patients younger than 55 years of age the overall satisfaction rate was $86 \%$ [29]. In our study, $87 \%$ of patients who responded were satisfied with their operated knee 2 years postoperatively, which is similar also to the satisfaction rates reported by Parvizi et al. (90\%), but somewhat higher compared to the satisfaction rates reported by Klit et al. (71\%) [10, 27]. Niemeläinen et al. reported 
Table 3 Binary logistic regression analysis to assess the association between preoperative factors and dissatisfaction and persistent pain after TKA

\begin{tabular}{|c|c|c|c|c|c|c|c|c|c|}
\hline \multirow[t]{2}{*}{ Variable } & \multicolumn{3}{|c|}{ Dissatisfaction } & \multicolumn{3}{|c|}{ Persistent pain during exercise } & \multicolumn{3}{|c|}{ Persistent pain at rest } \\
\hline & OR & $95 \% \mathrm{Cl}$ & $p$ & OR & $95 \% \mathrm{Cl}$ & $p$ & OR & $95 \% \mathrm{Cl}$ & $p$ \\
\hline \multicolumn{10}{|l|}{ Gender } \\
\hline Female & 1 & & & 1 & & & 1 & & \\
\hline Male & 1.64 & $0.68-3.96$ & 0.268 & 0.80 & $0.41-1.56$ & 0.526 & 1.06 & $0.39-2.89$ & 0.903 \\
\hline Higher BMI & 0.98 & $0.90-1.06$ & 0.588 & 1.02 & $0.96-1.08$ & 0.569 & 1.03 & $0.95-1.12$ & 0.513 \\
\hline Older age & 0.92 & $0.85-0.99$ & 0.029 & 0.93 & $0.87-0.99$ & 0.022 & 0.84 & $0.77-0.93$ & $<0.001$ \\
\hline At work & 0.53 & $0.21-1.33$ & 0.178 & 0.80 & $0.42-1.54$ & 0.507 & 1.77 & $0.43-7.34$ & 0.434 \\
\hline \multicolumn{10}{|l|}{ Alignment } \\
\hline Varus & 1 & & & 1 & & & 1 & & \\
\hline Valgus & 0.86 & $0.23-3.19$ & 0.818 & 1.01 & $0.41-2.50$ & 0.976 & 1.95 & $0.56-6.82$ & 0.296 \\
\hline \multicolumn{10}{|l|}{ KL-grade } \\
\hline $3-4$ & 1 & & & 1 & & & 1 & & \\
\hline 2 & 4.22 & $1.67-10.66$ & 0.002 & 1.51 & $0.69-3.33$ & 0.306 & 1.85 & $0.61-5.62$ & 0.275 \\
\hline \multicolumn{10}{|c|}{ Comorbidities } \\
\hline No & 1 & & & 1 & & & 1 & & \\
\hline Yes & 1.63 & $0.55-4.83$ & 0.377 & 0.92 & $0.36-2.33$ & 0.855 & 0.68 & $0.15-3.12$ & 0.615 \\
\hline
\end{tabular}

a satisfaction rate of $85 \%$ two years after surgery among patients aged less than 65 years comprising not only the patients of this study but also patients with unicompartmental and bilateral knee arthroplasties [11].

\section{Dissatisfaction and radiographic $O A$}

We found that dissatisfaction was significantly more common among patients with milder radiographic OA $29 \%$ in patients with KL 2 OA and only around $9 \%$ among patients with more severe OA. This finding is supported by Scott et al., who reported that over $50 \%$ of patients with KL 2 OA are dissatisfied after TKA [9]. A systematic review by Nakano et al. assessing dissatisfaction after TKA in patients of all ages had a similar finding as well [30]. Also Niemeläinen et al. found mild radiographic OA to be related to dissatisfaction [11]. We also found a trend for the KL3-4 subgroup to more often achieve clinically significant improvement in satisfaction (Table 2). This finding, however, lacked statistical significance, which may be due in part to the small size of the KL 2 subgroup and thus insufficient statistical power. Patients with milder OA tend to have comorbidities, such as depression, lower back pain and fibromyalgia, more often than those who have more severe OA [31]. These conditions are all causes of psychological distress, and thus lead to difficulties in coping with pain [32]. In our study there was no difference in the prevalence of comorbidities between KL subgroups, though patients reported only conditions that limited their physical activity more than their knee OA. In previous studies, milder OA has also been associated with worse functional outcomes after TKA and an increased risk for

Table 4 Association of preoperative PROMs with dissatisfaction and persistent pain after TKA

\begin{tabular}{|c|c|c|c|c|c|c|c|c|c|}
\hline \multirow[t]{2}{*}{ Variable } & \multicolumn{3}{|c|}{ Dissatisfaction } & \multicolumn{3}{|c|}{ Persistent pain during exercise } & \multicolumn{3}{|c|}{ Persistent pain at rest } \\
\hline & $\overline{O R}$ & $95 \% \mathrm{Cl}$ & $\overline{p \text {-value }}$ & $\overline{O R}$ & $95 \% \mathrm{Cl}$ & $p$-value & $\overline{O R}$ & $95 \% \mathrm{Cl}$ & $\overline{p \text {-value }}$ \\
\hline OKS & 0.94 & $0.87-1.01$ & 0.067 & 0.95 & $0.90-1.00$ & 0.062 & 0.88 & $0.81-0.96$ & 0.004 \\
\hline KOOS pain & 0.96 & $0.93-0.99$ & 0.003 & 0.97 & $0.95-0.99$ & 0.004 & 0.95 & $0.91-0.98$ & 0.002 \\
\hline KOOS symptoms & 0.96 & $0.93-0.99$ & 0.003 & 0.97 & $0.94-0.99$ & 0.002 & 0.95 & $0.91-0.98$ & 0.002 \\
\hline KOOS ADL & 0.97 & $0.94-0.99$ & 0.011 & 0.98 & $0.96-1.00$ & 0.045 & 0.97 & $0.94-0.99$ & 0.022 \\
\hline KOOS sport & 0.95 & $0.91-0.99$ & 0.032 & 0.95 & $0.92-0.98$ & 0.002 & 0.94 & $0.89-0.99$ & 0.040 \\
\hline KOOS QoL & 0.99 & $0.96-1.02$ & 0.629 & 0.98 & $0.96-1.00$ & 0.108 & 0.98 & $0.95-1.02$ & 0.358 \\
\hline RAND-36 MCS & 0.99 & $0.97-1.01$ & 0.247 & 0.99 & $0.98-1.01$ & 0.208 & 0.98 & $0.96-1.00$ & 0.054 \\
\hline RAND-36 PCS & 0.97 & $0.94-1.00$ & 0.080 & 0.98 & $0.96-1.00$ & 0.065 & 0.96 & $0.93-1.00$ & 0.047 \\
\hline
\end{tabular}


revision surgery $[33,34]$. Overall, this evidence strongly suggests that TKA should be mainly performed for patients with KL 3 or 4 knee OA. Furthermore, if patients with KL 2 knee OA are scheduled for TKA, they should be thoroughly informed about the increased likelihood of dissatisfaction after such surgery.

\section{Dissatisfaction: age and BMI}

We also found that younger age increases the risk for dissatisfaction. This finding is in line with the findings of Lange et al., who included a matched control group of older patients aged 65-75 years in their study and found patients aged 55 years or less to be more dissatisfied with their TKA (satisfaction $86 \%$ vs. 91\%) [35]. This finding might have to do with younger patients' higher expectations and requirements for physical activities after surgery [7-10]. Haynes et al. reported that younger patients still do achieve a clinically significant improvement after TKA, even though they tend to have less severe radiographic $\mathrm{OA}$ and more severe clinical symptoms than older patients before surgery [18]. Unlike Scott et al. or Nakano et al., we found that BMI had no association with dissatisfaction $[9,30]$. Therefore, although obesity is a well-known risk factor for knee OA and the risk for both prosthetic joint infection and revision surgery is markedly increased among obese patients, based on this study they seem to be as satisfied with the outcome of TKA as non-obese patients[21, 36].

\section{Dissatisfaction, persistent pain and PROMs}

Similarly to the findings of Scott et al., we also found a trend for worse preoperative OKS being associated with dissatisfaction [9]. However, the association was more significant with OKS and persistent pain at rest. Also, apart from KOOS Quality of Life, all KOOS subscores were statistically significantly related to dissatisfaction and persistent pain. These findings support the prevalent conception that severe preoperative knee pain, along with pain elsewhere in the body, predicts persistent pain after TKA [32].

In this study, multiple standardised PROMs (OKS, KOOS, RAND-36) were collected and analysed, but all in all the associations found with dissatisfaction and persistent pain seem somewhat scattered. Some previous studies have tried to identify threshold values for preoperative OKS that indicate postoperative satisfaction but found no association between these two variables $[37,38]$. In our study, KOOS was more strongly associated with dissatisfaction and persistent pain than OKS. This finding may favour KOOS as a more knee symptom-specific score in screening. KOOS includes questions that cover a wider spectrum regarding pain and functional outcome compared to OKS. KOOS also assesses the effect of the knee on quality of life.
Conversely, OKS is a markedly shorter questionnaire (12 vs. 36 items), and thus it is easier for patients to fill out. Moreover, OKS was also recently chosen as the preferred condition-specific instrument for the continuous evaluation of outcomes after TKA [39]. Still, altogether these findings indicate that although PROMs are commonly used in the evaluation of outcomes after knee arthroplasty, none of them are ideal in preoperatively identifying those patients who will be dissatisfied and will have persistent pain after surgery. Therefore, they should not be the main focus in the selection of patients for TKA. Even though it is important to keep evaluating patient satisfaction and surgery outcomes, it seems that instead of using a vast battery of questionnaires, simple outcome measures, such as VAS and OKS or KOOS, would be adequate, as recently proposed by an OECD working group [39].

\section{Limitations and strengths}

Our study was a prospective observational study that used multiple standardised PROMs. We acknowledge a few limitations in our study. First, our study lacked a control group comprising patients over the age of 65 . This would have enabled us to compare the results between these two age groups. Second, an additional weakness in our study was the limited sample size, which suffered from 14 (7\%) patients missing critical data. Thus, for some comparisons, our study might have been inadequately powered to find significant differences. We also did not discuss patient expectations which might have been a confounding factor. Additionally, we analysed mainly self-reported data and outcome at 2 years and therefore were not able to evaluate immediate postoperative complications, infections, tromboembolisms or other adverse events that might have affected the results. Also, comorbidities were self-reported and limited to conditions limiting patient's physical activity more than their knee OA. Thus, mental health issues, chronic pain and other conditions predisposing to persistent pain and dissatisfaction might not have been considered. Our study also had some obvious strengths. The study population consisted of non-selected real-world patients, and therefore, along with the study setup, was equivalent to everyday clinical practice. Additional strengths of the study were the 2-year follow-up period and the high response rate - only $4 \%$ of patients were lost to follow-up during the study.

\section{Conclusions}

We found that a vast majority of patients aged less than 65 years clearly benefit from TKA surgery in terms of pain relief, improved function and overall satisfaction. Dissatisfaction in this age group seems to be strongly related to mild radiographic OA. Thus, TKA should 
primarily be performed for patients with end-stage OA. Although severe preoperative knee pain is shown to be related to both dissatisfaction and persistent pain, based on the findings of the present study, the value of PROMs in predicting these outcomes remains uncertain. Further research with a lot larger patient cohorts on PROMs' value in predicting satisfaction is certainly needed to provide support for the surgical decision making.

\section{Acknowledgements}

Not applicable.

\section{Authors' contributions}

All authors contributed to the study. MN and AE designed the study. $\mathrm{HH}$, MN and SL analysed the data and calculated statistics. SL and MN prepared the manuscript and AE reviewed the results. All authors revised and approved the final manuscript.

\section{Funding}

Not applicable.

\section{Availability of data and materials}

The datasets used and analysed during the current study are available from the corresponding author on reasonable request.

\section{Declarations}

\section{Ethics approval and consent to participate}

The study protocol (R11178) was approved by the Ethics Committee of Pirkanmaa Hospital District under which Coxa Hospital for Joint Replacement operates. The study was retrospectively registered with ClinicalTrials.gov (registration number NCT03233620) on 28/07/2017. All patients gave written informed consent to participate in the study.

\section{Consent for publication}

Not applicable.

\section{Competing interests}

$\mathrm{SL}, \mathrm{MN}, \mathrm{HH}$ have no competing interests. AE: Institutional research grants: DePuy Synthes and Zimmer Biomet. Lecture fees, Zimmer Biomet.

\section{Author details}

${ }^{1}$ Coxa Hospital for Joint Replacement, Tampere, Finland. ${ }^{2}$ Faculty of Medicine and Health Technologies, Tampere University, Tampere, Finland. ${ }^{3}$ Faculty of Social Sciences, Tampere University, Tampere, Finland.

Received: 7 November 2020 Accepted: 8 July 2021

Published online: 05 August 2021

\section{References}

1. Kurtz S, Ong K, Lau E, Mowat F, Halpern M. Projections of primary and revision hip and knee arthroplasty in the United States from 2005 to 2030. Bone Joint Surg. 2007:89:780-5

2. Niemelälnen MJ, MäKelä KT, Robertsson O, W-Dahl A, Furnes O, Fenstad AM, Pedersen AB, Schrøder HM, Huhtala H, Eskelinen A. Different incidences of knee arthroplasty in the Nordic countries. Acta Orthop. 2017:88:173-8.

3. Singh JA, Yu S, Chen L, Cleveland JD. Rates of total joint replacement in the United States: future projections to 2020-2040 using the national inpatient sample. J Rheumatol. 2019;46:1134-40.

4. Carr AJ, Robertsson O, Graves S, Price AJ, Arden NK, Judge A, Beard DJ. Knee replacement. Lancet. 2012;379:1331-40.

5. Julin J, Jämsen E, Puolakka T, Konttinen YT, Moilanen T. Younger age increases the risk of early prosthesis failure following primary total knee replacement for osteoarthritis. Acta Orthop. 2010;81:413-9.

6. Meehan J, Danielsen B, Kim S, Jamali A, White R. Younger age is associated with a higher risk of early periprosthetic joint infection and aseptic mechanical failure after total knee arthroplasty. J Bone Joint Surg. 2014:96: 529-35.
7. Noble PC, Conditt MA, Cook KF, Mathis KB. The John Insall Award: Patient expectations affect satisfaction with total knee arthroplasty. Clin Orthop Relat Res. 2006;452:35-43.

8. Scott CEH, Bugler KE, Clement ND, MacDonald D, Howie CR, Biant LC. Patient expectations of arthroplasty of the hip and knee. J Bone Joint Surg Br. 2012;94:974-81.

9. Scott CEH, Oliver WM, MacDonald D, Wade FA, Moran M, Breusch SJ. Predicting dissatisfaction following total knee arthroplasty in patients under 55 years of age. Bone Joint J. 2016;98-B:1625-34.

10. Parvizi J, Nunley R, Berend K, Lombardi A Jr, Ruh E, Clohisy J, Hamilton W, Della Valle C, Barrack R. High level of residual symptoms in young patients after total knee arthroplasty. Clin Orthop Relat Res. 2014;472:133-7.

11. Niemeläinen M, Moilanen $\mathrm{T}$, Huhtala $\mathrm{H}$, Eskelinen A. Outcome of knee arthroplasty in patients aged 65 years or less: a prospective study of 232 patients with 2-year follow-up. Scand J Surg. 2019:108:313-20.

12. Voutilainen A, Pitkäaho T, Kvist T, Vehviläinen-Julkunen K. How to ask about patient satisfaction? The visual analogue scale is less vulnerable to confounding factors and ceiling effect than a symmetric Likert scale. J Adv Nurs. 2016:72(4):946-57.

13. Myles PS, Myles DB, Galagher W, Boyd D, Chew C, MacDonald N, Dennis A. Measuring acute postoperative pain using the visual analog scale: the minimal clinically important difference and patient acceptable symptom state. Br J Anaesth. 2017;118:424-9.

14. Murray DW, Fitzpatrick R, Rogers K, Pandit H, Beard DJ, Carr AJ, Dawson J. The use of the oxford hip and knee scores. J Bone Joint Surg Br. 2007;89(8): $1010-4$

15. Roos EM, Toksvig-Larsen S. Knee injury and osteoarthritis outcome score (KOOS) - validation and comparison to the WOMAC in total knee replacement. Health Qual Life Outcomes. 2003;1:17.

16. Ware J, Sherbourne C. The MOS 36-item short-form health survey (SF-36). I. Conceptual framework and item selection. Med Care. 1992;30:473-83.

17. Kellgren JH, Lawrence JS. Radiological assessment of osteo-arthrosis. Ann Rheum Dis. 1957;16:494-502

18. Haynes J, Sassoon A, Nam D, Schultz L, Keeney J. Younger patients have less severe radiographic disease and lower reported outcome scores than older patients undergoing total knee arthroplasty. Knee. 2016;24:663-9.

19. Blagojevic M, Jinks C, Jeffery A, Jordan KP. Risk factors for onset of osteoarthritis of the knee in older adults: a systematic review and metaanalysis. Osteoarthr Cartil. 2010;18:24-33.

20. Srikanth VK, Fryer JL, Zhai G, Winzenberg TM, Hosmer D, Jones G. A metaanalysis of sex differences prevalence, incidence and severity of osteoarthritis. Osteoarthr Cartil. 2005;13:769-81.

21. Zheng $\mathrm{H}$, Chen $\mathrm{C}$. Body mass index and risk of knee osteoarthritis: systematic review and meta-analysis of prospective studies. BMJ Open. 2015:5:e007568.

22. Ministry of Social Affairs and Health, Finland. Medical Research Act. English translation available online at https://www.finlex.fi/en/laki/kaannokset/1999/ en19990488_20100794.pdf. Accessed 21 May 2021

23. von Elm E, Altman DG, Egger M, Pocock SJ, Gøtzsche PC, Vandenbroucke JP, STROBE Initiative. The Strengthening the Reporting of Observational Studies in Epidemiology (STROBE)statement: guidelines for reporting observational studies. Lancet. 2007;370(9596):1453-7.

24. W-Dahl A, Robertsson O, Lidgren L. Surgery for knee osteoarthritis in younger patients. Acta Orthop. 2010;81:161-4.

25. Sihvonen R, Paavola M, Malmivaara A, Itälä A, Joukainen A, Nurmi H, Kalske J, Järvinen TLN. Arthroscopic partial meniscectomy versus sham surgery for a degenerative meniscal tear. N Engl J Med. 2013;369:2515-24.

26. Niinimäki TT, Eskelinen A, Mann BS, Junnila M, Ohtonen $P$, Leppilahti J. Survivorship of high tibial osteotomy in the treatment of osteoarthritis of the knee: finnish registry-based study of 3195 knees. J Bone Joint Surg Br. 2012;94:1517-21.

27. Klit J, Jacobsen S, Rosenlund S, Sonne-Holm S, Troelsen A. Total knee arthroplasty in younger patients evaluated by alternative outcome measures. J Arthroplasty. 2014;29:912-7.

28. Goh GS, Liow MH, Abd Razak HR, Tay DK, Lo NN, Yeo SJ. Patient-reported outcomes, quality of life and satisfaction rates in young patients aged 50 years or younger after total knee arthroplasty. J Arthroplasty. 2016:32:41925.

29. Aujla RS, Esler CN. Total knee arthroplasty for osteoarthritis in patients less than fifty-five years of age: a systematic review. J Arthroplasty. 2017:32(8): 2598-603. 
30. Nakano N, Shoman H, Olavarria F, Matsumoto T, Kuroda R, Khanduja V. Why are patients dissatisfied following a total knee replacement? A systematic review. Int Orthop. 2020;44:1971-2007.

31. Jacobs CA, Christensen CP, Karthikeyan T. Chronic non-orthopedic conditions more common in patients with less severe degenerative changes that have elected to undergo total knee arthroplasty. J Arthroplasty. 2015;30:1146-9.

32. Lavand'homme P, Thienpont E. Pain after total knee arthroplasty: a narrative review focusing on the stratification of patients at risk for persistent pain. Bone Joint J. 2015;97-B:45-8.

33. Peck CN, Childs J, McLauchlan GJ. Inferior outcomes of total knee replacement in early radiological stages of osteoarthritis. Knee. 2014;21: 1229-32.

34. Riis A, Rathleff MS, Jensen MB, Simonsen O. Low grading of the severity of knee osteoarthritis pre-operatively is associated with a lower functional level after total knee replacement: a prospective cohort study with 12 months' follow-up. Bone Joint J. 2014;96-B:1498-502.

35. Lange JK, Lee YY, Spiro SK, Haas SB. Satisfaction rates and quality of life changes following total knee arthroplasty in age-differentiated cohorts. Arthroplasty. 2018;33(5):1373-8.

36. Kulkarni K, Karssiens T, Kumar V, Pandit H. Obesity and osteoarthritis. Maturitas. 2016:89:22-8.

37. Judge A, Arden NK, Price A, Glyn-Jones S, Beard D, Carr AJ, Dawson J, Fitzpatrick R, Field RE. Assessing patients for joint replacement: can preoperative Oxford hip and knee scores be used to predict patient satisfaction following joint replacement surgery and to guide patient selection? J Bone Joint Surg Br. 2011;93:1660-4.

38. Clement N, MacDonald D, Burnett R. Predicting patient satisfaction using the Oxford knee score: where do we draw the line? Arch Orthop Trauma Surg. 2013;133:689-94.

39. Canadian Institute for Health Information, Organisation for Economic Cooperation and Development. OECD Patient-Reported Indicator Surveys (PaRIS) Initiative: Patient-Reported Outcome Measures (PROMs) for hip and knee replacement surgery - international data collection guidelines. Ottawa: $\mathrm{ClH} ; 2019$

\section{Publisher's Note}

Springer Nature remains neutral with regard to jurisdictional claims in published maps and institutional affiliations.

Ready to submit your research? Choose BMC and benefit from:

- fast, convenient online submission

- thorough peer review by experienced researchers in your field

- rapid publication on acceptance

- support for research data, including large and complex data types

- gold Open Access which fosters wider collaboration and increased citations

- maximum visibility for your research: over $100 \mathrm{M}$ website views per year

At $\mathrm{BMC}$, research is always in progress.

Learn more biomedcentral.com/submissions 